\title{
Bottom-Up, Top-Down, and the Messy Reality of the In-Between
}

\author{
RICHARD MOHLER, AIA, Associate Professor; Principal \\ University of Washington \& Mohler + Ghillino Architects
}

\section{INTRODUCTION}

This paper reflects my recent five-year experience as a practicing architect, educator and advocate embedded in the contentious fray of public discourse regarding housing and land use policy in Seattle. During this period I testified before city council regarding proposed housing-focused land use legislation, presented my analysis of that policy in professional and community forums, published opinion pieces in the Seattle Times, coordinated the housing advocacy efforts of AIA Seattle, conducted graduate-level design studios focused on the topic at the University of Washington, and presented the student work (often with students) in venues throughout the city. I ended this period of local advocacy in 2018, when I was appointed to the Seattle Planning Commission, although I continue to help coordinate AIA Seattle's advocacy efforts as co-chair of its Public Policy Board.

This paper is also a response to the premise behind the symposium title: "Bottom-Up Social Change." The notion of a purely "bottom-up" or "top-down" effort to upend the sociopolitical status quo does not align with my recent experience. In fact, I often found it was difficult, if not impossible, to discern which parties constituted the "bottom" and which the "top", despite their competing claims to be the genuine voice of grass roots democracy. Further, I found a number of instances in which a "top-down" effort engendered a wave of unified "bottom-up" activism that was previously disconnected, if it existed at all.

Though I am not an expert in public policy matters, a limited review of current academic and professional literature tends to confirm my recent experience. Policy experts generally acknowledge that the distinction between bottom-up and top-down advocacy is murky at best and most efforts employ a combination of both strategies. ${ }^{1}$ This is particularly the case as an effort expands beyond an individual project to more sweeping public policy concerns at the city or regional scale. The point of this paper is not to advocate for either strategy but, rather, to illustrate that the reality is a messy "in-between" that often conflates the two.

More importantly, this is a call for architects and educators to enter the fray of public policy discourse for several reasons. First, it is an opportunity for us to leverage our unique skill sets in untangling what are often convoluted, contradictory and fiercely contested issues. Second, it engages us in a process that will ultimately determine the policy frameworks within which we will be working. Third, not doing so risks distancing us from the decisions that will have the greatest impact on our built environment and could further call the relevance of our discipline into question.

\section{SEATTLE HOUSING CONTEXT}

Like many cities, Seattle has experienced a meteoric rate of growth and the transportation and housing affordability challenges that come with it. However, these challenges are exacerbated by a number of context specific factors. Seattle is bounded by mountains and water. This, coupled with a state growth management act, mandates that the city grow by becoming denser rather than expanding outward and it is doing so at a faster rate than any other major U.S. city. ${ }^{2}$ Seattle has experienced the largest percentage population growth of any of the country's 50 largest cities over the past decade. ${ }^{3}$ It has the 8th most expensive rental housing market, the 7th most expensive home ownership market and the third highest number of people experiencing homelessness (behind only New York and Los Angeles), despite being only the 18th largest U.S. city by population. ${ }^{4}$

A third of Seattle metro households are cost burdened by housing and a fifth are severely so, meaning that these households spend more than half of their income on housing. ${ }^{5}$ The county in which Seattle is located has a current deficit of 156,000 rent-restricted housing units, according to the King County Affordable Housing Task Force. This deficit is anticipated to expand to 244,000 rent-restricted units by 2040.6 Assuming a conservative estimate of $\$ 300,000$ per unit, this shortfall will require roughly $\$ 70$ billion in funding over the next 20 years, an even larger amount than will be spent on regional light rail and bus rapid transit in the same timeframe.

\section{SEATTLE RESPONSE}

In September of 2014, then Seattle Mayor Ed Murray assembled a committee of 28 volunteers including developers of market-rate and affordable housing, contractors, architects, environmental and social justice advocates, labor, tenant and neighborhood representatives and experts in private and public financing to develop strategies to address Seattle's housing affordability crisis (Figure 1). After eight months of deliberations 


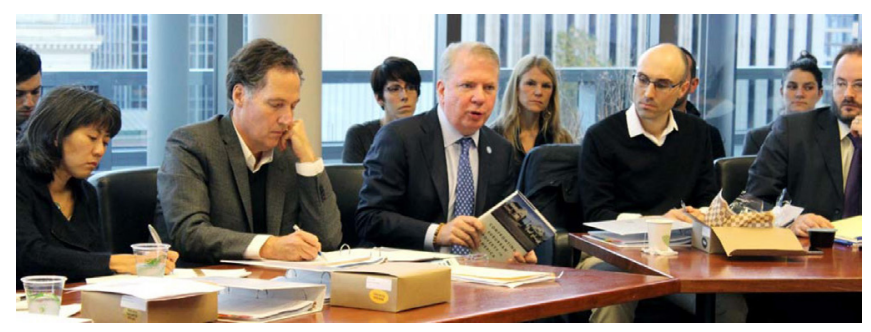

Figure 1. Seattle Mayor's Housing Affordability and Livability (HALA) Committee. (Credit: City of Seattle)
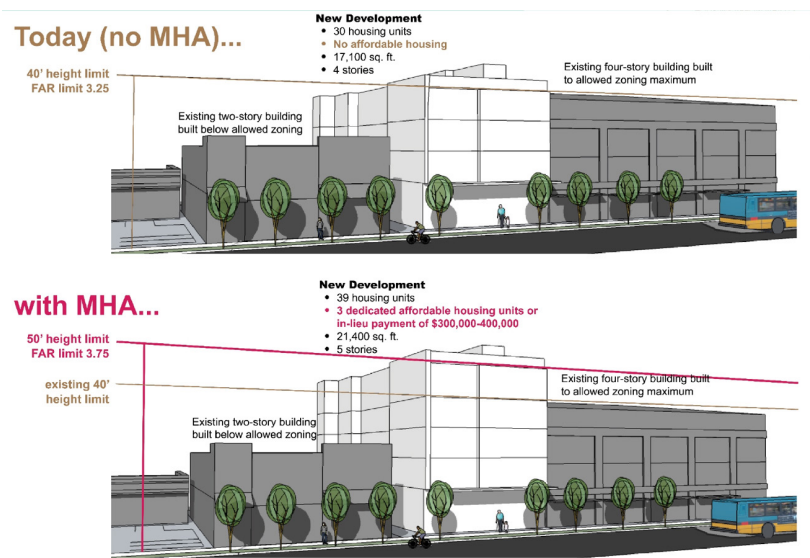

Figure 2. Mandatory Housing Affordability (MHA) provides additional building height and floor area ratio (FAR) in exchange for affordable housing units on-site or payment into a city fund to build affordable housing. (Credit: City of Seattle)

the committee released the Housing Affordability and Livability Agenda or HALA. HALA is a suite of 65 recommendations covering land use and building code reform, tax incentives, financing and funding strategies and tenant protections - all focused on addressing the housing crisis.

But one recommendation, leaked to a columnist for the Seattle Times, nearly doomed HALA before it was even released. The recommendation to allow for duplexes and triplexes in the city's single-family zones - which accounts for three quarters of the city's residential land - was described by the columnist as a war on Seattle's neighborhood character. ${ }^{7}$ That recommendation was also a tacit repudiation of a deal made in the mid-1990s. Then, in response to the newly enacted State Growth Management Act, the city embarked on a neighborhood planning effort that gave neighborhood community councils - representing single-family homeowners almost exclusively - the latitude to dictate urban growth strategies that preserved one house per lot in areas zoned "single family." The resulting outcry to the recommendation compelled the mayor to promptly rescind it for fear of losing the entire effort to homeowner discontent.
However, the mayor's own HALA-inspired program, known as Mandatory Housing Affordability, proved controversial as well. MHA is an inclusionary zoning strategy that is simple in concept but extremely complex in its implementation. In exchange for increased development capacity (typically an additional floor), developers are required to provide rentrestricted housing units at $60 \%$ of area median income on-site or pay into a fund that the city will use to build affordable housing at the same income level (Figure 2). MHA applies to all multi-family and commercial projects citywide and, in tandem with other city programs, is anticipated to produce roughly 20,000 units of affordable housing over the next decade. ${ }^{8}$

Despite resistance from some members of the market-rate development community as well as a large swath of Seattleites resistant to urban growth and density, MHA passed relatively quickly in downtown and other high density commercial districts. However, in districts within or adjacent to single family neighborhoods it was a very different story.

\section{NEIGHBORHOOD RESISTANCE}

The mid-1990's neighborhood planning effort mentioned above resulted in what came to be called the "urban village" growth strategy. This strategy locates housing density in close proximity to transit and commercial services in nodes ranging from the most dense, urban centers, to the least dense, residential urban villages, which are surrounded by singlefamily zoned areas that are off-limits to multifamily structures. There are 17 such residential urban villages citywide and one of them, Wallingford, is where I live.

The mayor's MHA proposal called for a modest upzone across all urban villages, in exchange for including a stipulated number of affordable units on-site or funding for them to be built elsewhere. This included residential urban villages that bordered or, as in the case of Wallingford, contained parcels zoned single-family within it. It was this proposal to upzone the single-family parcels within Wallingford's urban village boundary to multi-family that engendered vociferous resistance from homeowners.

To express its discontent, the homeowner-dominated Wallingford Community Council at one city outreach event staged a mock funeral for "the neighborhood voice" (Figure 3). This ambitious piece of political theater condemned the city's "top-down" planning strategy as a death knell to the neighborhood voice and, indeed, to democracy itself. The protesters cast their city council representative, who chaired the committee sponsoring MHA, as the grim reaper seizing the neighborhood's soul as they ceremoniously carried a coffin into the city proceedings. While city staff in attendance insisted the coffin be promptly removed, the point had been made: Top-down government policy had killed the bottom-up neighborhood voice. 


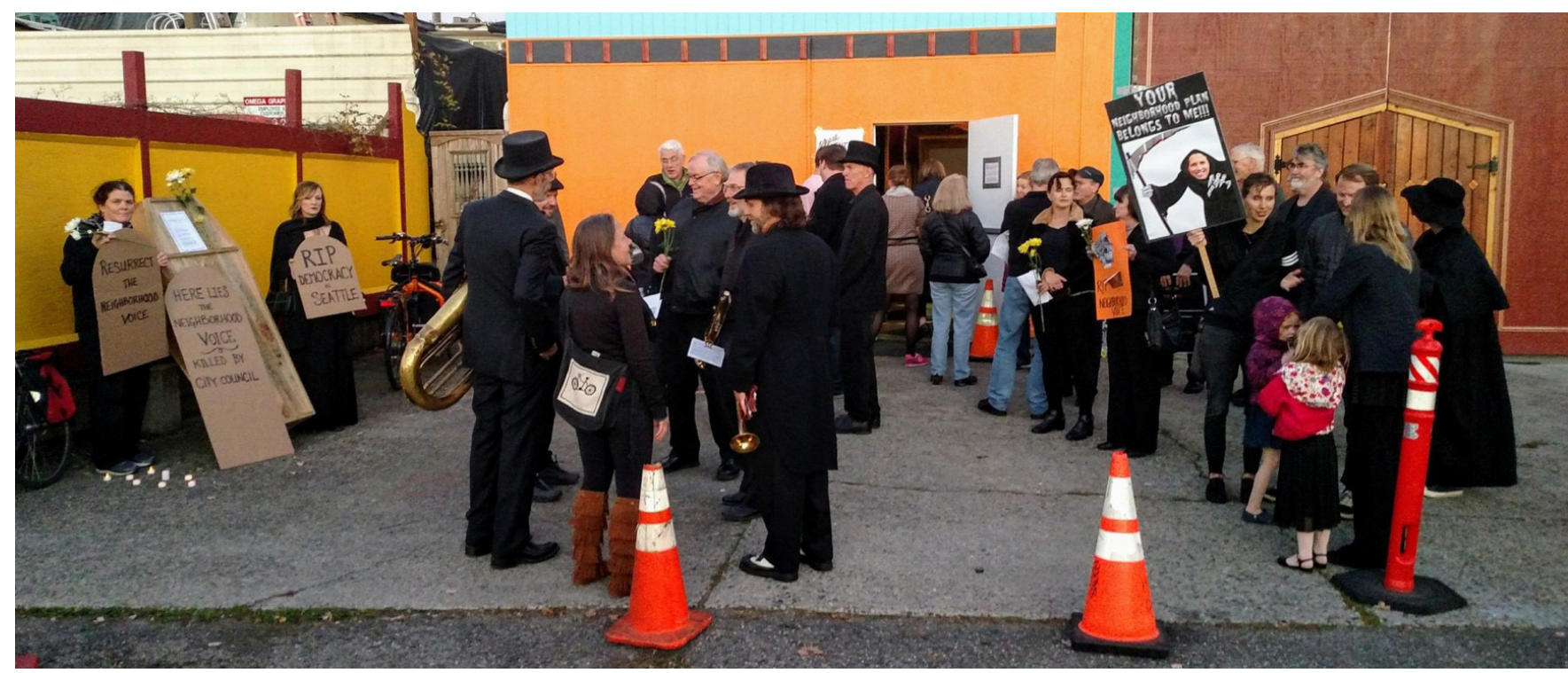

Figure 3. The Wallingford Community Council stages a mock funeral for the "Neighborhood Voice" outside a City of Seattle HALA/MHA public outreach event. (Credit: Doug Trumm)

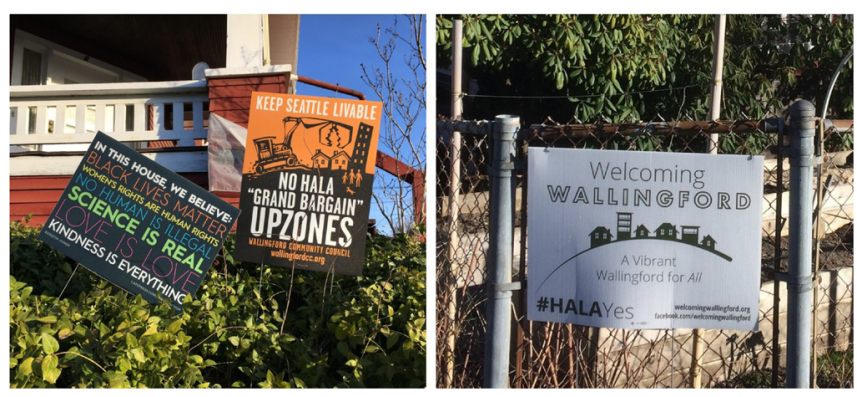

Figure 4. A tale of two yard signs. The Wallingford Community Council denounces the HALA/MHA upzones (left) while another neighborhood group, Welcoming Wallingford, supports them (right). (Credit: Rick Mohler/Steve Hurd)

However, there is more than one narrative in this drama. On the left (Figure 4) is a Wallingford Community Council yard sign found throughout the neighborhood denouncing the HALA upzones. On the right, is a yard sign found throughout the neighborhood in support of them. The latter is from an alternative neighborhood group, Welcoming Wallingford; in the interest of full disclosure, I was a founding member. Welcoming Wallingford supports the upzones as a strategy to allow more people of varying incomes to have access to the frequent transit, walkable commercial district, parks and schools that the neighborhood abundantly provides.

These competing yard signs illustrate the difficulty in identifying bottom-up versus top-down strategies and the groups that promote them. The Wallingford Community Council denounces the "top-down" land use policy for ignoring the community voice yet it has maintained a decadeslong legacy of dictating local land use policy to suit the will of its single-family home owning membership. Welcoming Wallingford, on the other hand, is an ad hoc collection of renters and homeowners that supports what is clearly a "top-down" land use proposal as a legitimate and necessary challenge to the socio-political status quo. Which is bottom-up versus top-down?

Welcoming Wallingford is only one of many pro-housing grassroots groups that emerged to advocate for HALA's "topdown" recommendations following its release. It appears that HALA gave a voice, or at least a platform, to many who felt they had neither beforehand. However, it did something more. It created alignments between those advocating for housing affordability and other previously misaligned grassroots advocacy groups including those advancing equitable transit, cycling, neighborhood greenways and broader environmental concerns such as climate change. HALA compelled these groups to realize, for the first time, that housing and density were central to all of their missions. Again, which is bottom-up versus top-down?

\section{ACADEMIC ENGAGEMENT}

In addition to my own involvement in the public policy debate, I've employed University of Washington architecture design studios in the interest of exposing students to the messy fray of public policy-making. The studios also serve to expand and enhance the community dialogue by providing creative illustrations of what these policies might entail. One such studio was launched the fall quarter of 2015, just three months after HALA's release. The studio focused on the Wallingford urban village and tasked students with envisioning strategies 

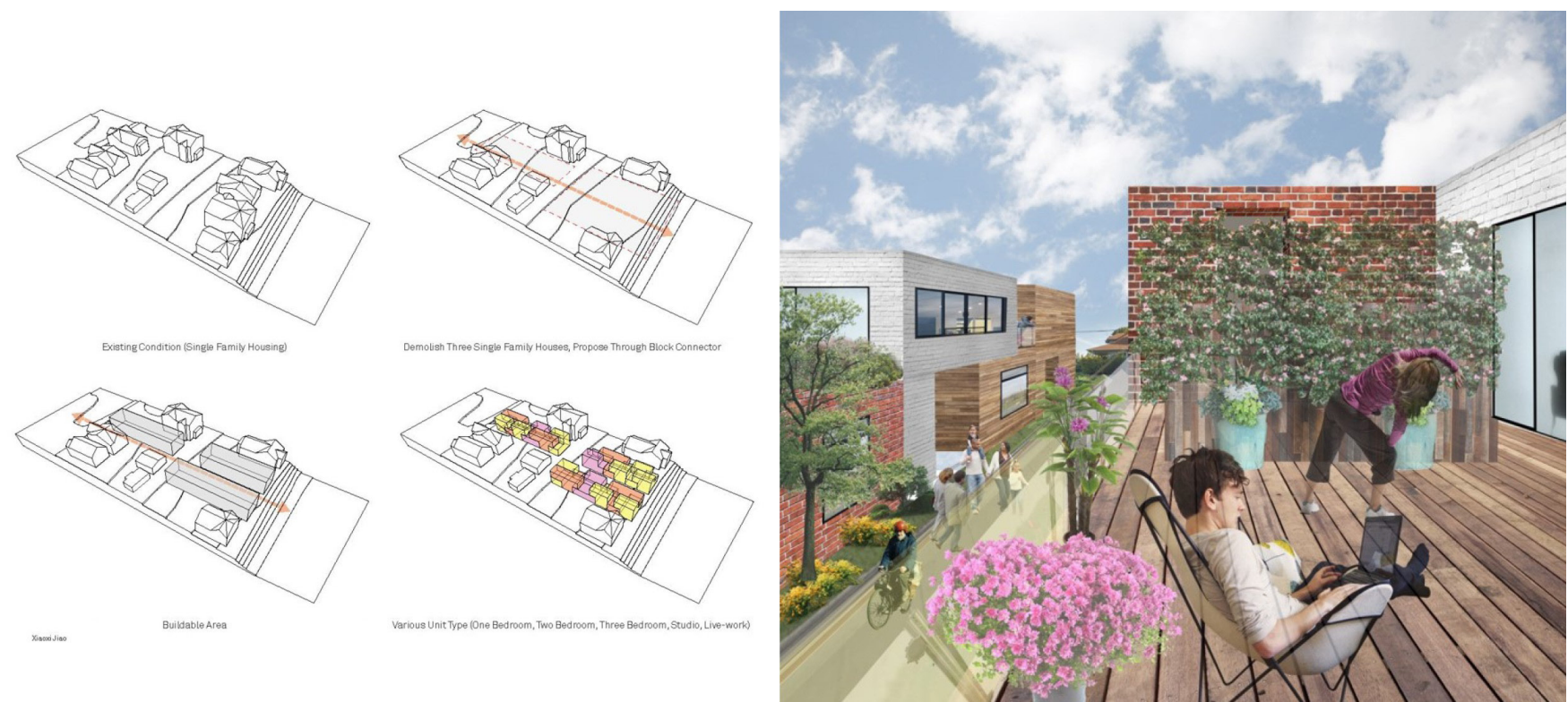

Figure 5. Neighborhood pedestrian thruway with increased housing density. (Credit: Xiaoxi Jiao)

to increase the quantity and variety of housing types while enhancing the quality of life for all neighbors.

A proposal by Xiaoxi Jiao (Figure 5) recognized that many blocks in the northern parts of Wallingford are quite long some in excess of 600 feet - reducing the neighborhood's urban porosity and walkability. In response, she proposed a new network of intimately-scaled green pedestrian thruways bisecting the unusually long blocks. The walkways are lined with small, interlocking 1, 2, and 3 bedroom units with roof decks instead of yards. This provides an entirely new pedestrian experience within the neighborhood while adding up to twenty new housing units per block.

A project by Siyu Qu (Figure 6) proposes a new courtyard housing type to be located along arterial streets that nearly triples the density of its half-block site. In the interest of increasing pedestrian access and light and air to the units, the project introduces a new network of alleys to the neighborhood which, again, increases porosity while increasing light, air and privacy for adjacent parcels.

Students presented this work to members of the HALA committee in the final review and at two city-sponsored HALA outreach events where they were able to engage with neighbors on a one-on-one basis. I presented the work at a Seattle Town Hall event to about 1,000 members of the broader community.

A year later, UW faculty colleague Elizabeth Golden and I taught a studio to test the specific, proposed MHA land use code changes in several other residential urban villages throughout the city. The studio worked closely with Blokable,

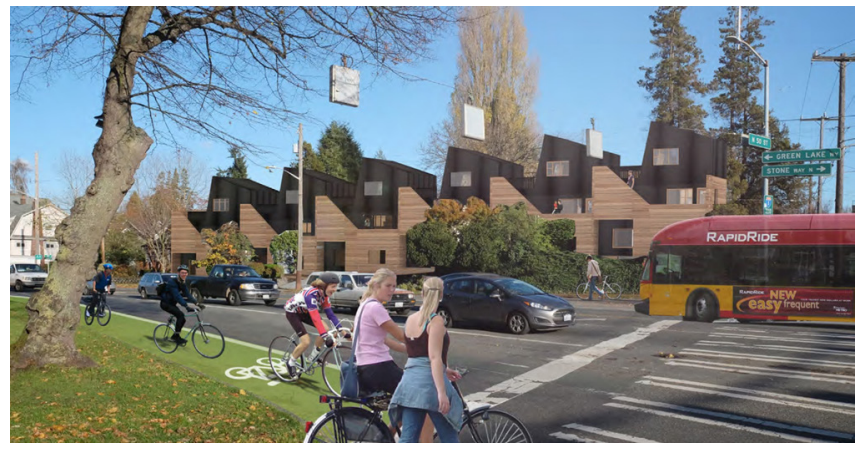

Figure 6. New courtyard housing on arterial street. (Credit: Siyu Qu)

a Seattle modular pre-fab start-up, and their in-house designer, Yasaman Esmaili, to explore the impact of modular pre-fabrication on housing design.

In one urban village a project by Carolyn McGunagle (Figure 7) proposes clusters of stacked and rotated modular flats that ensure privacy for each unit while maintaining neighborhood scale at quadruple its existing density. In a different and denser urban village, a proposal by Christian Reyling (Figure 8) explores the potential of modularity in a five-story micro-housing block adjacent to an existing south-facing community garden. Elizabeth, Yasaman and I presented this work at AIA Seattle's annual Housing Design Forum in 2018 to an engaged audience of residential architects that was not as informed of these proposed polices as one might expect. ${ }^{9}$ The studio was also referenced in a Seattle Times article on emerging architectural approaches shaping the city's residential landscape. ${ }^{10}$ 


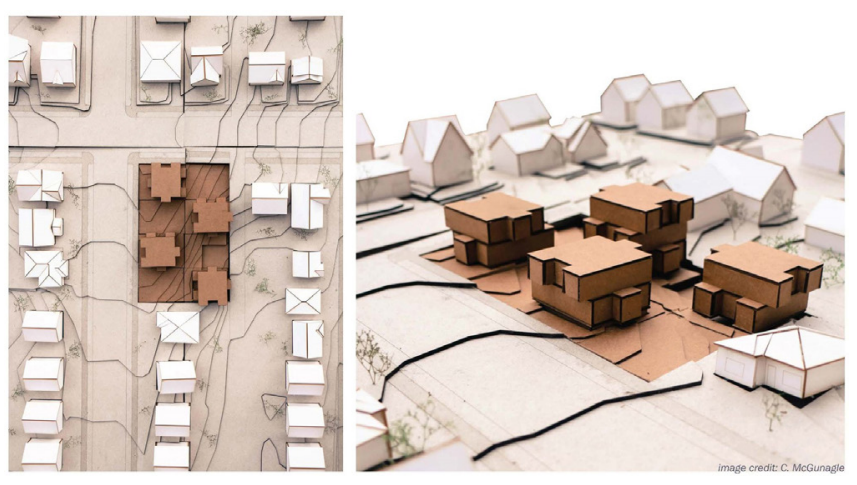

Figure 7. Stacked and rotated modular pre-fab flats on corner site with alley. (Credit: Carolyn McGunagle)

\section{NEXT STEPS}

As mentioned, I was appointed to the Seattle Planning Commission in 2018. The commission consists of sixteen volunteers from a range of disciplines including planning, architecture, transportation, public health and housing. The commission is appointed by the city council and mayor and it advises both parties as the steward of Seattle's Comprehensive Plan. However, the commission has no legislative authority as this is the purview of elected officials.

While individual members of the Seattle Planning Commission are precluded from lobbying on behalf of outside advocacy groups, the commission itself is now advocating for increased land use flexibility, not only in Seattle's residential urban villages, but in all of its single-family zones. In December 2018, the commission released a report, called "Neighborhoods for All: Expanding Housing Opportunity in Seattle's SingleFamily Zones," that offers a series of broad observations and potential strategies for gently increasing density in singlefamily neighborhoods city-wide. ${ }^{12}$ Along with similar efforts in Portland, OR and Minneapolis, MN, the report is garnering national attention as the social equity and environmental sustainability implications of single-family zoning are becoming increasingly apparent.

The commission is currently engaged in a community outreach effort that will entail presentations and discussions with scores of community councils, grass roots advocacy groups and other interested parties city-wide over the next six months. The goal of the outreach effort is to gather concerns, ideas and aspirations from as wide an array of stakeholders as possible. This information will inform the next phase of the commission's work, which is to develop a more specific set of urban design frameworks and policy tools that will view this issue through the combined lenses of social equity, sustainability and livability. The intention is to inform and influence city council and the mayor's office to take action on reforms to single-family zoning as they consider the next round of major updates to the city's comprehensive plan. The comprehensive plan, in turn, will guide specific land-use policy in neighborhoods city-wide.

In the winter quarter of 2020 I will teach a research design studio and companion seminar at the University of Washington titled "The Rise and Fall of Single-Family Zoning". The seminar will delve into the socio-political context in which single-family zoning came into existence and its roots in racial and class exclusion and it will acknowledge that this legacy continues today, regardless of our intentions. The studio will advance and apply strategies outlined in the planning commission's report while investigating similar efforts in other cities, including Portland's Residential Infill Project and Minneapolis' 2040 Comprehensive Plan.

I'm currently working closely with planning commissioners and commission staff in developing the curriculum and establishing guidelines for studio deliverables. The goal is to have the studio at least inform and, ideally, be part of, the next phase of the commission's work. As in previous studios focused on these issues, the enthusiasm, energy, creativity and, perhaps most importantly, visualizations that students bring to these efforts are invaluable in fostering an inclusive conversation that helps to erode the understandable fear of the unknown often at the core of one's resistance to change.

\section{CONCLUSION}

Returning to our original theme, one might ask whether this partnership between the planning commission and university is a bottom-up or top-down effort to drive social change. I could make an argument either way, but in the end, is this the question one should be asking?

One could argue that the commission, given its level of expertise and appointment by elected officials, constitutes the "top." On the other hand, the commission's charge is to ensure that elected officials adhere to the mandates of the city's comprehensive plan, and its focus on equitable development, regardless of the political pressure they face. The academy could also be construed as the "top" although, in this case, much of the work will be conducted by students who, by nature of their age, may be most impacted by the policies that are ultimately put in place.

What other constituencies are we striving to serve and is there an unrepresented "bottom" that we hope to speak on behalf of versus the voices of privilege that identify themselves as such? Can we, as academics and professionals, be honest brokers among these competing interests or do we engage more as an act of self-preservation focused on shaping the environment within which we work?

The fray of public discourse regarding any policy change, and especially those at the scale mandated by the significant social equity and environmental challenges we face, is confusing, complex, nuanced, non-linear and iterative. What matters more than a distinction between "bottom-up" and "top-down" 


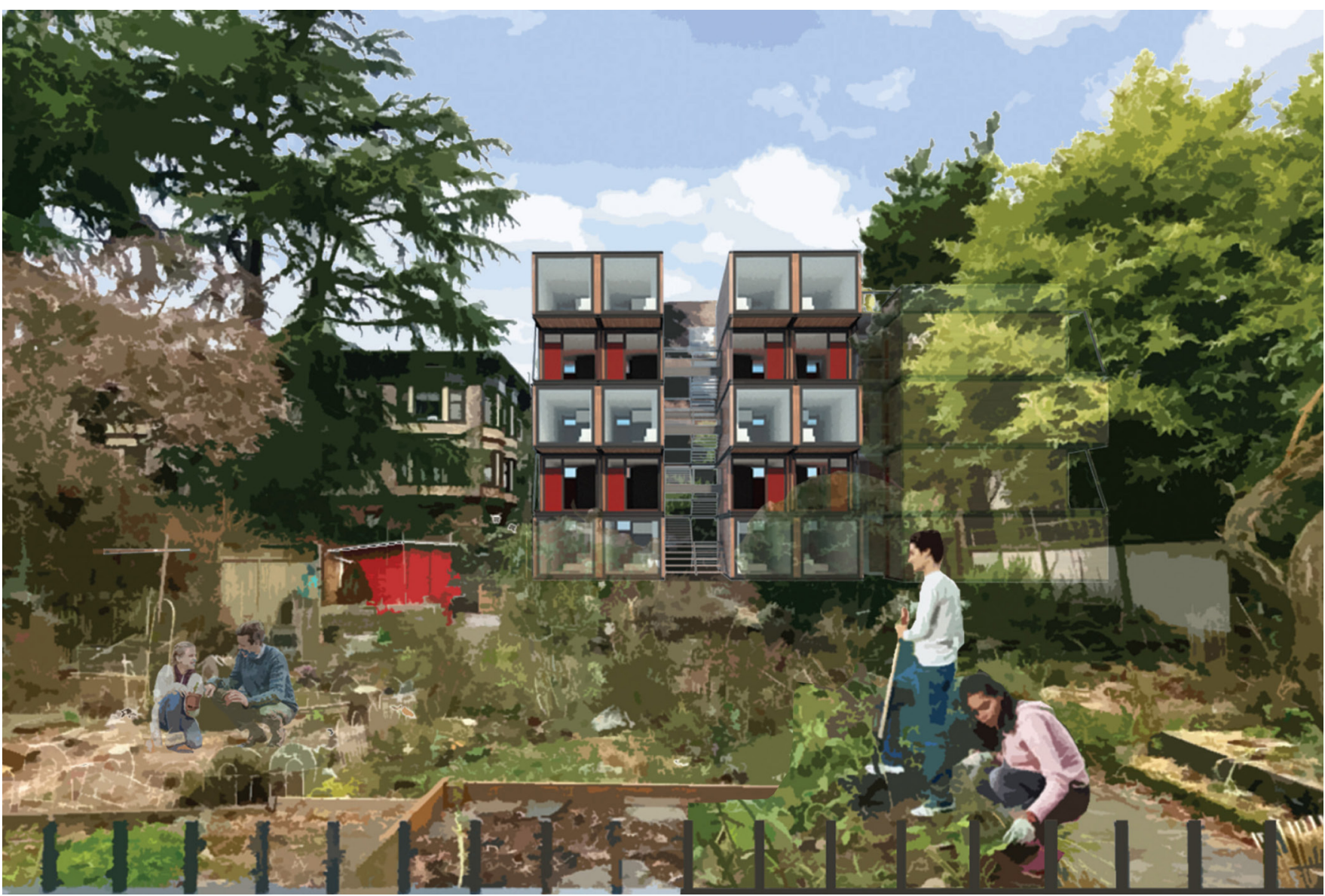

Figure 8. Stacked modular pre-fab micro-housing overlooking and existing community garden. (Credit: Christian Reyling)

social change is the efficacy of the policy being considered when viewed through the lens of social equity, that genuine and effective community outreach strategies are employed and that the outreach has a meaningful and measurable impact on the proposed policy.

What also matters is that architects, educators and students enter the fray and engage in the discourse, one which will inevitably expand and become more heated as our housing crisis does the same on a national level. We have much to offer. As architects, we understand the need for a collective vision, that change is constant (it's our line of work) and that every decision entails a trade-off between competing interests and priorities. We are respected for this knowledge and we should leverage this respect, from "bottom" to "top," within our communities.

\section{ENDNOTES:}

1. Biswambhar Panda, "Top Down or Bottom Up? A Study of Grassroots NGOs' Approach," Journal of Health Management, 9, 2, (2007): 257-273.

2. Carina Wong, "Top-down or Bottom-up: Is it Really a Choice?", Alliance Magazine, April 1, 2016, https://www.alliancemagazine.org/blog/ top-down-or-bottom-up-is-it-really-a-choice/.
3. Benjamin Kumpf, "Bottom-up, Top-down and Outside-in: Cultivating Innovation at UNDP", Medium, July 3,2018, https://medium.com/@UNDP/bottom-up-topdown-and-outside-in-cultivating-innovation-at-undp-7d4935c56f9c.

4. Jed Kolko, "Seattle Climbs but Austin Sprawls: The Myth of the Return to Cities," New York Times, May 22, 2017.

5. Gene Balk, "114,000 More People: Seattle Now Decade's Fastest-Growing Big City in All of U.S.," Seattle Times, May 24, 2018.

6. Kate Walters, "Seattle Homeless Population is Third Largest in U.S., after LA and NYC," KUOW, December 18, 2018, https://www.kuow.org/stories/ here-s-how-seattle-and-washington-compare-to-national-homeless-trends.

7. Sarah Anne Lloyd, "One-third of Seattle-area Households are Burdened by Housing Costs," Curbed Seattle, June 25, 2018, https://seattle.curbed. com/2018/6/25/17501872/seattle-area-housing-cost-burden.

8. King County Comprehensive Plan Update, Technical Appendix B-Housing, March 2016, https://www.kingcounty.gov/ /media/depts/executive/ performance-strategy-budget/regional-planning/2016CompPlanUpdate/ ExecRecommend2016CompPlan/TechAppend BHousing2016KCCP.ashx?la=en.

9. Danny Westneat, "Get Rid of Single-family Zoning? These Conversations Shouldn't be Secret," Seattle Times, July 7, 2015.

10. City of Seattle, Housing Affordability and Livability Agenda, July 13, 2015, https://www.seattle.gov/Documents/Departments/HALA/Policy/HALA_ Report_2015.pdf.

11. AlA Seattle, Inspiration, Innovation, Impact: The Future of Residential Design, May 7, 2018, https://www.aiaseattle.org/event/housingforum2018/.

12. Sandy Deneau Dunham, " 5 Architectural Approaches that are Shaping the Way We Live," Seattle Times, September 12, 2018.

13. Seattle Planning Commission, "Neighborhoods for All: Expanding Housing Opportunity in Seattle's Single-Family Zones," Fall 2018, https://www. seattle.gov/Documents/Departments/SeattlePlanningCommission/ SPCNeighborhoodsForAllFINALdigital2.pdf. 